\title{
Spaceborne Radar Subsurface Imaging in Hyperarid Regions
}

\author{
CHARLES ELACHI, SENIOR MEMBER, IEEE, LADISLAV E. ROTH, MEMBER, IEEE, AND GERALD G. SCHABER
}

\begin{abstract}
Imaging data acquired with the Shuttle Imaging Radar (SIR-A) over the hyperarid region of Egypt/Sudan clearly show surface penetration through the sand cover. Even though absorption does occur in the sand layer, surface refraction leads to a steeper incidence angle at the sand/bedrock interface resulting in a stronger backscatter. A simple backscatter model shows that for a low-loss thin sand layer the presence of the covering layer enhances the capability to image the subsurface interface, particularly at large incidence angles and $\mathrm{HH}$ polarization.
\end{abstract}

\section{INTRODUCTION}

$\mathrm{I}^{\mathrm{N}}$ N A RECENT paper, McCauley et al. [5] reported that the radar images of southern Egypt (Fig. 1) acquired with the Shuttle Imaging Radar (SIR-A) clearly showed subsurface features (Fig. 2) which are covered by a thin layer (fraction to a few meters thickness) of dry sand. The presence of these features, which include drainage channels, faults, and terraces, has long been suspected. However, the features were visible neither on Landsat images nor in the field because of the omnipresent sand cover. The area imaged is part of the Selima sand sheet, near the Egyptian/Sudanese/Libyan border. This area forms the core of the most arid region in the world, where rainfall is estimated to occur at about 30- to 50-year intervals. Laboratory measurements of the complex dielectric constant of sand samples from the area in question showed that at $L$-band, the SIR-A frequency, the skin depth ranges from 1.5 to $6 \mathrm{~m} \mathrm{[6]}$. Field observations by two of the authors (C. Elachi and G. Schaber) showed that the sand layer thickness ranges from 0.8 to $2 \mathrm{~m}$. In a more recent paper, Blom et al. [1] observed the penetration effect in the Seasat radar imagery taken over the Means Valley, Mojave Desert, Southern California, where the cover thickness (but not necessarily the texture) is comparable to that in southern Egypt.

The SIR-A is a synthetic aperture imaging radar with $\mathrm{HH}$ polarization and $50^{\circ}$ incidence angle at the surface. It was flown on the second Shuttle flight in November 1981, and acquired surface images with a 40-m resolution. For the description of the mission, see Elachi et al. [4].

In this short paper, we show that the low-loss sand layer

Manuscript received April 6, 1983; revised December 1, 1983. This work was performed at the Jet Propulsion Laboratory, California Institute of Technology, and was supported by NASA under contract NAS7-100.

C. Elachi and L. Roth are with the Jet Propulsion Laboratory, California Institute of Technology, Pasadena, CA 91109.

G. G. Schaber is with the United States Geological Survey, Flagstaff, AZ 86001 .

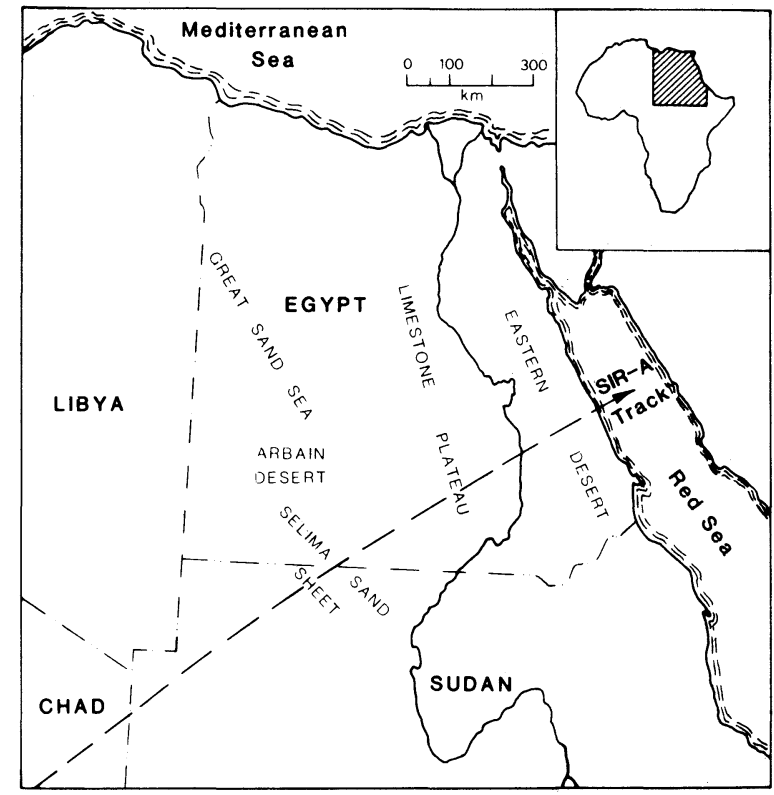

Fig. 1. Index map of NE Africa showing the axis of the SIR-A swath; STS-2, Rev. 27. Images shown in Fig. 2 (a) and (b) were taken in the area of the Selima Sand Sheet, south of the Arbain Desert.

could enhance the capability to image the subsurface features, due to the refraction at the air-sand interface. The refraction results in a smaller effective incidence angle and a stronger backscatter which can compensate both for the losses due to absorption in the sand layer and the reflection at the air-sand interface.

\section{Formulation for Direct Polarization BACKSCATTER}

The backscatter cross section of a slightly rough surface is given by [7], [8]

$$
\sigma_{s}=f_{i}\left(\epsilon_{1}, \lambda, \theta\right) W(2 k \sin \theta)
$$

where $\epsilon_{1}$ is the real part of the dielectric constant of the medium, $\lambda$ is the wavelength of the incident wave, $\theta$ is the incidence angle (see Fig. 3(a)), $k=2 \pi / \lambda$ is the wave number of the incident wave, $W(k)$ is the surface roughness spectrum, and $f_{i}$ is a function given by

$$
f_{H}=4 \pi k^{4} \cos ^{4} \theta\left[\frac{\epsilon_{1}-1}{\left(\cos \theta+\sqrt{\left.\epsilon_{1}-\sin ^{2} \theta\right)^{2}}\right.}\right]^{2}
$$



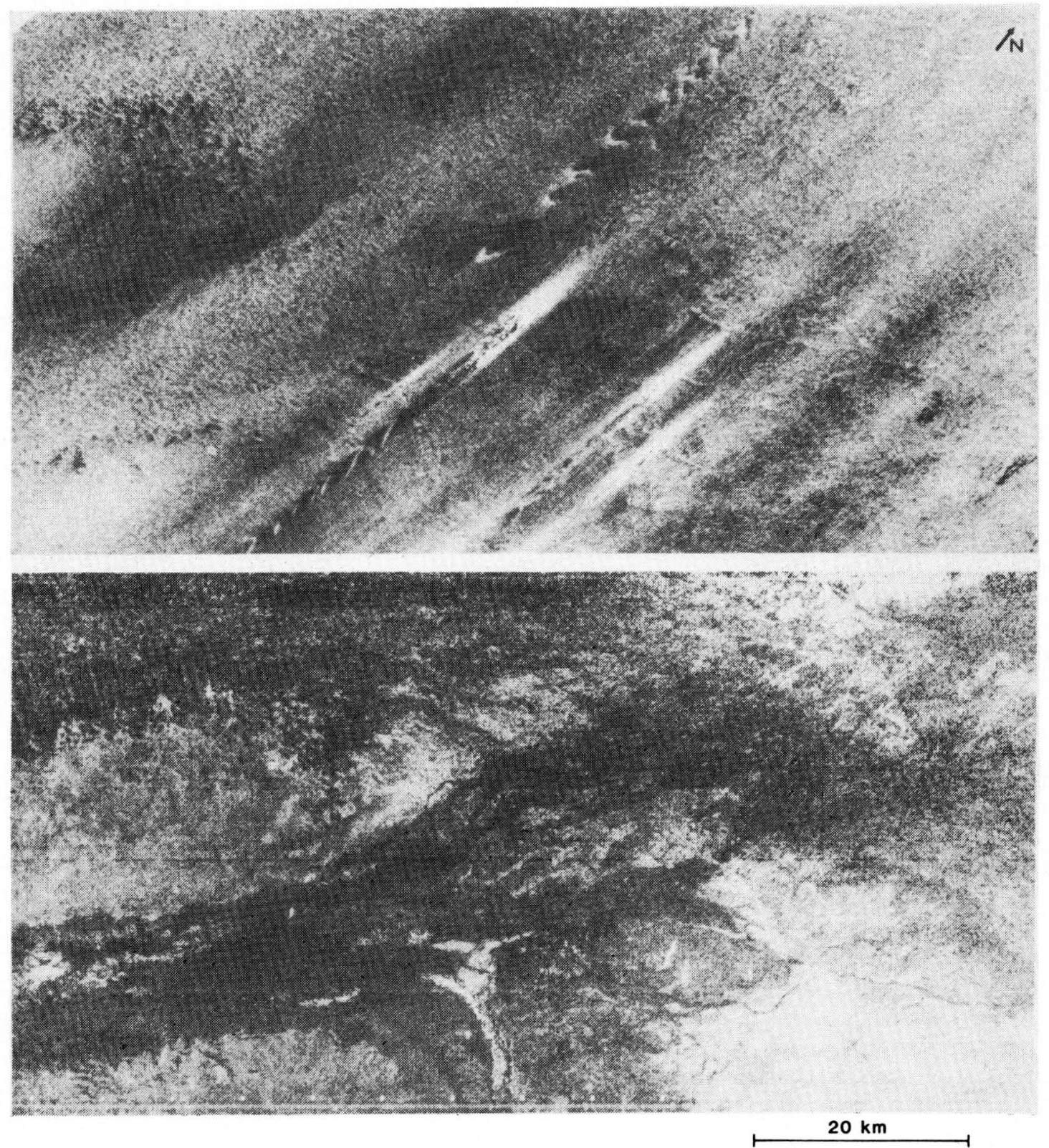

(a)

Fig. 2. (a) SIR-A (top) and Landsat (bottom) images of a $50 \times 100 \mathrm{~km}$ area at the Egyptian/Sudanese border. The Landsat image shows a landscape dominated by aeolian processes. The Selima Sand Sheet blankets the underlying material with windblown sand, to a few meters in thickness. Presently active dunes marching across the sand sea are visible as the diagonal streaks near the image center. In contrast, the SIR-B image reveals a landscape carved by fluvial processes, and now buried beneath the sand. The confluence of what were two large rivers is shown in the center of the SIR-A image. Note that the dunes in the Landsat image have no expression on the SIR-A image. SIR-A image from data take 28 , Rev. 27, acquired November 14, 1981. Landsat band 6 image, November 11, 1972.

for horizontal polarization, and

$$
f_{V}=4 \pi k^{4} \cos ^{4} \theta\left[\frac{\left(\epsilon_{1}-1\right)\left\{\epsilon_{1}+\left(\epsilon_{1}-1\right) \sin ^{2} \theta\right\}}{\left(\epsilon_{1} \cos \theta+\sqrt{\epsilon_{1}-\sin ^{2} \theta}\right)^{2}}\right]^{2}
$$

for vertical polarization. In the presence of a sand layer of thickness $L$, dielectric constant $\epsilon_{2}$, and skin depth $d$, the backscatter cross section becomes (see Fig. 3(b))

$$
\begin{aligned}
\sigma_{s s}= & T_{i}^{2}(\theta) e^{-2 L / d \cos \theta^{\prime}} f_{i}\left(\frac{\epsilon_{1}}{\epsilon_{2}}, \frac{\lambda}{\sqrt{\epsilon_{2}}}, \theta^{\prime}\right) \\
& \cdot W\left(2 k \sqrt{\epsilon_{2}} \sin \theta^{\prime}\right)
\end{aligned}
$$

where $T(\theta)$ is the transmission coefficient at the surface [2], and $\sin \theta=\sqrt{\epsilon_{2}} \sin \theta^{\prime}$. The relation (4) shows that the roughness term $W$ is identical in both the expression for $\sigma_{s}$ and $\sigma_{s s}$. Thus the effect of the layer can be characterized by the ratio $R$

$$
R=\frac{\sigma_{s S}}{\sigma_{s}}=T_{i}^{2}(\theta) e^{-2 L / d \cos \theta^{\prime}} \frac{f_{i}\left(\frac{\epsilon_{1}}{\epsilon_{2}}, \frac{\lambda}{\sqrt{\epsilon_{2}}}, \theta^{\prime}\right)}{f_{i}(\epsilon, \lambda, \theta)} .
$$

The behavior of $R$ as a function of $L, \theta, d$, and $\epsilon_{1}$ is shown in Figs. 4, 5, and 6. Fig. 4 corresponds to an incidence angle of $50^{\circ}$ (SIR-A incidence angle). The sand layer is taken to have 

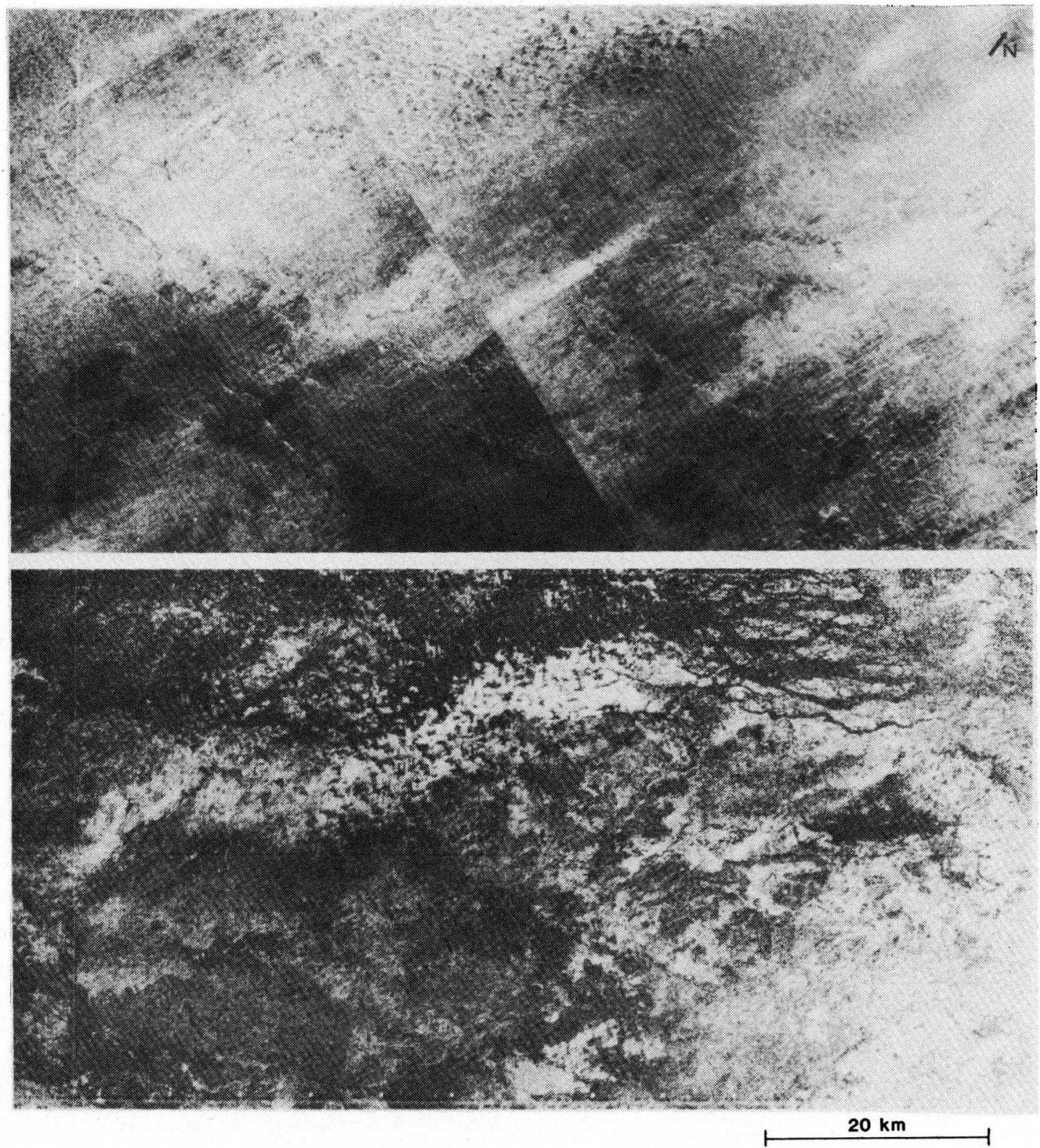

(b)

Fig. 2. (b) SIR-A (top) and Landsat (bottom) images of an area in southwestern Egypt. Once again, the Landsat image primarily shows a landscape dominated by aeolian processes, with dunes and the sand sheet forming most of the visible features. The SIR-A image reveals fluvial landforms buried by the sands. Note in particular the braided stream channels near the top of the SIR-A image. The line on the Landsat image is a slight break in the mosaic, the effect of which is heightened by the disparate sun angles. SIR-A image from data take 28, acquired November 14, 1981. Landsat band 6 image, Feb. 9, 1973. Images courtesy of R. Blom, JPL.

$\epsilon_{2}=2.5$ which is consistent with the dielectric constant of most powdered rocks [3]. This gives a refracted angle, which is also the incidence angle at the subsurface interface, of $29^{\circ}$. The subsurface dielectric constant is taken as $\epsilon_{1}=8$. This value falls within the range of dielectric constants measured for solid mafic rocks [3]. Fig. 4 shows that the presence of a sand layer of up to $\frac{2}{3}\left(\frac{1}{4}\right)$ of the skin depth will in effect enhance the capability to image the subsurface interface with $\mathrm{HH}$ polarization (VV polarization). For a skin depth of $6 \mathrm{~m}$, this favorable effect will occur for sand layers up to $4 \mathrm{~m}$ thick for $\mathrm{HH}$, and $1.5 \mathrm{~m}$ thick for $\mathrm{VV}$.
Fig. 5 illustrates the layer enhancement effect as a function of incidence angle for the case of $\epsilon_{2}=2.5$ and $\epsilon_{1}=8$. It shows that even though the absolute backscatter cross section decreases as a function of $\theta$, the presence of a dry sand layer and the resulting refraction effect will enhance the capability to image the subsurface, particularly at large incidence angles. For $L / d=0.2$, and the chosen values of the dielectric constants, enhancement occurs at all angles. For $L / d=0.8$, enhancement occurs at incidence angles larger than $58^{\circ}$ for $\mathrm{HH}$ and larger than $78^{\circ}$ for VV. The enhancement is strongly dependent on the dielectric discontinuity $\left(\epsilon_{1}-\epsilon_{2}\right)$. This is 


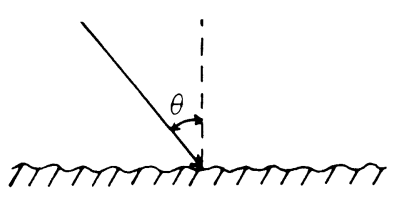

$\varepsilon$

(a)

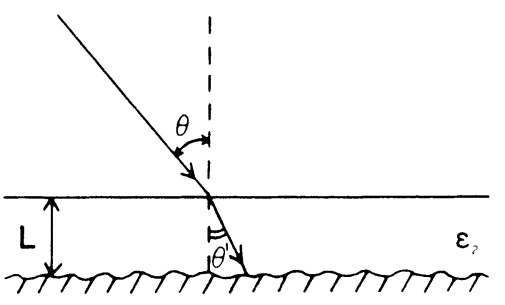

$\varepsilon$

(b)

Fig. 3. Geometry of the wave ray. (a) Exposed rough surface of dielectric constant $\epsilon_{1}$; (b) a layer of sand of thickness $L$ and dielectric constant $\epsilon_{2}$ covers the rough surface.

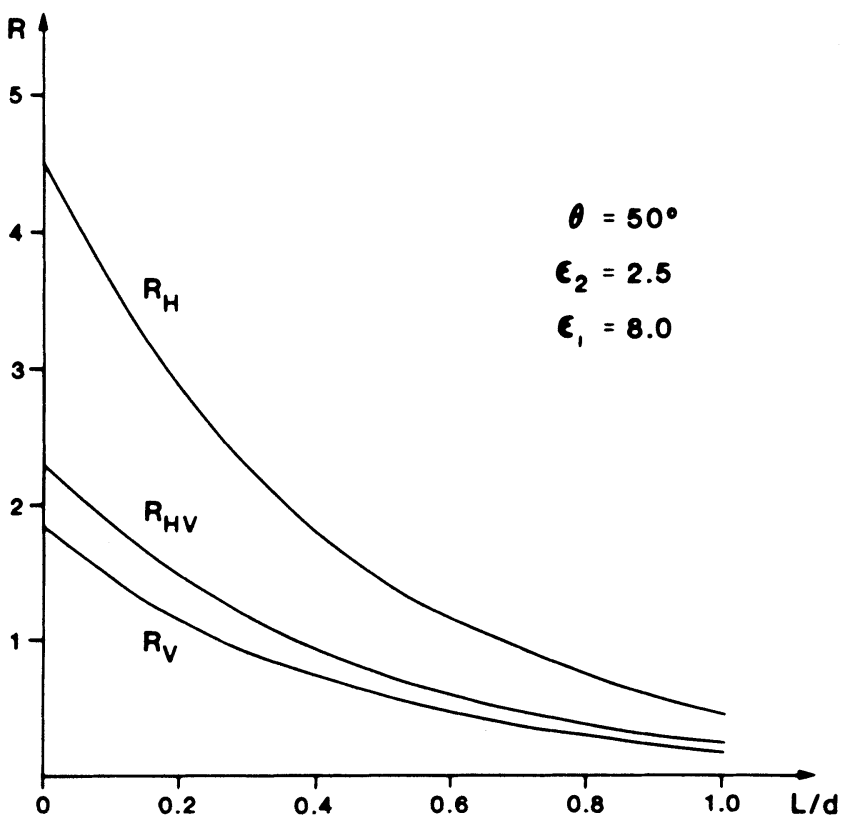

Fig. 4. Ratio $R$ of the backscatter cross section of the covered surface $\sigma_{s s}$ over the backscatter cross section of the uncovered surface $\sigma_{s}$. For small value of $L / d(d=$ skin depth), $R$ is larger than 1 because of the enhancement due to surface refraction. As $L / d$ increases, the absorption losses in the sand become dominant, cancelling the favorable refraction effect.

illustrated in Fig. 6. As the dielectric constant $\epsilon_{1}$ increases above 4 , which would be the case for almost all solid rocks, $R_{H}$ is always larger than 1 for $L / d=0.2$ and $\theta=50^{\circ}$. In the case of $L / d=0.8$, this enhancement occurs only for $\epsilon_{1}$ larger than 12 which is not a common case. For the vertical polarization, the enhancement is less favorable.

\section{Formulation for Cross Polarized BACKSCATTER}

In the case of the cross polarized cross section, $\sigma_{s}^{\prime}$ is given by [7] [8]

$$
\sigma_{s}^{\prime}=g(\epsilon, \lambda, \theta) I
$$

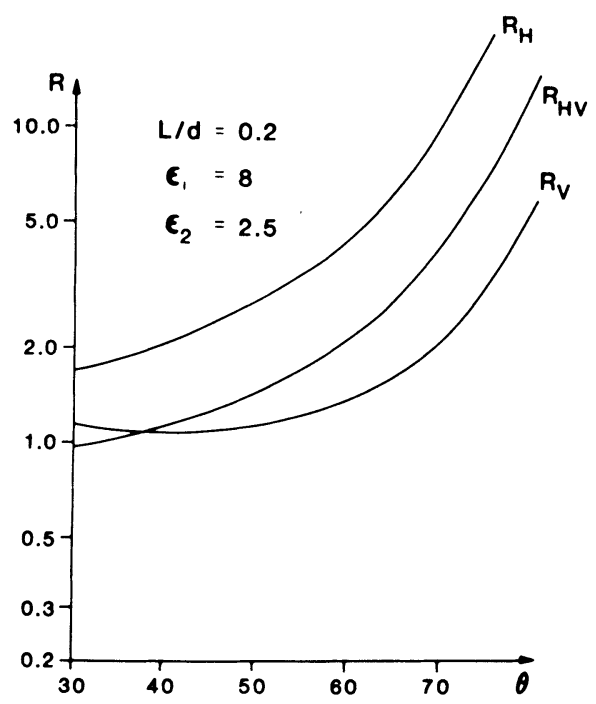

(a)

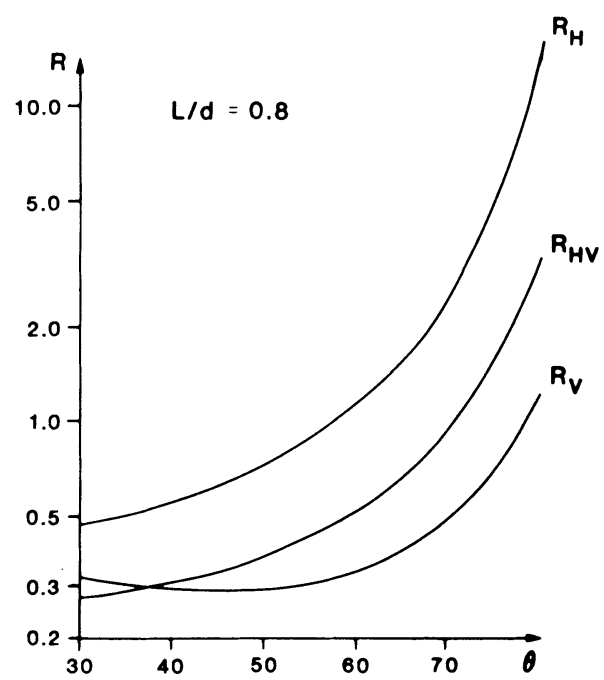

(b)

Fig. 5. Behavior of $R$ as a function of $\theta$ for different values of $L / d$. (a) For $L / d=0.2, R_{H}, R_{H V}$ are larger than 1 for all values of $\theta$. (b) For $L / d=0.8$ the enhancement effect occurs only at large incidence angles.

where

$$
\begin{aligned}
& g= 2 \pi k^{8} \cos ^{4} \theta \\
& \cdot \frac{(\epsilon-1)^{4}\left(\epsilon-\sin ^{2} \theta\right)}{\left(\cos \theta+\sqrt{\left.\epsilon-\sin ^{2} \theta\right)^{2}}\left(\epsilon \cos \theta+\sqrt{\epsilon-\sin ^{2} \theta}\right)^{2}\right.}
\end{aligned}
$$

and $I$ is the surface roughness autocorrelation. The ratio $R_{H V}$ for the layer-covered interface is then

$$
\begin{aligned}
R_{H V}= & \frac{\sigma_{s s}^{\prime}}{\sigma_{s}^{\prime}}=T_{H}(\theta) T_{V}(\theta) e^{-2 L / d \cos \theta^{\prime}} \\
& \cdot \frac{g\left(\frac{\epsilon_{1}}{\epsilon_{2}}, \frac{\lambda}{\sqrt{\epsilon_{2}}}, \theta^{\prime}\right)}{g\left(\epsilon_{1}, \lambda, \theta\right)} .
\end{aligned}
$$

The behavior of $R_{H V}$ is also shown in Figs. 5 and 6. In general, it can be said that the cross polarized signal enhancement is weaker than in the case of the direct $\mathrm{HH}$ polarized signal but stronger than in the case VV polarized signal. 

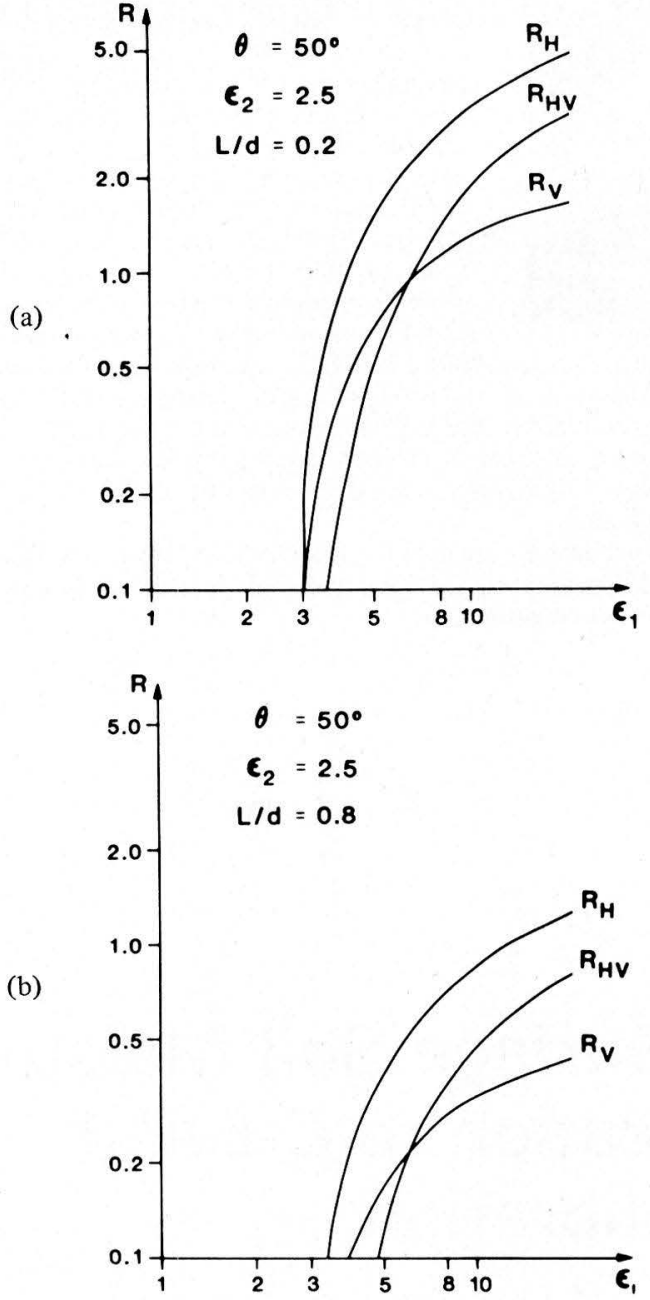

Fig. 6. Behavior of $R$ as a function of $\epsilon_{1}$, for $\epsilon_{2}$ fixed at 2.5 and $\theta$ at $50^{\circ}$. (a) $L / d=0.2 ;$ (b) $L / d=0.8$.

\section{SUMmARY}

In summary, the SIR-A imagery of the hyperarid region in Egypt clearly verifies what has been suspected, based on theoretical consideration, that imaging radar can image subsurface features when they are covered with a thin layer of low-loss material. This was reconfirmed by analyzing some Seasat data that were taken prior to the SIR-A mission. The presence of a thin low-loss layer in many cases enhances the return signal due to refraction at the surface interface. This enhancement effect is most pronounced in the $\mathrm{HH}$ polarization and at large incidence angles. A key factor is that the surface layer be characterized by a very low loss tangent, which implies a very low moisture content (less than 1 percent). This was the case in the Egyptian desert as well as in the Means Valley.

More detailed investigations of the hyperarid regions of the world are planned during the SIR-B mission which is scheduled to take place in August 1984. During the SIR-B mission, surface images will be acquired at 6 different incidence angles ranging from $15^{\circ}$ to $60^{\circ}$.

The hyperarid regions are mainly located in northern Africa, and along the western coasts of sourthern Africa and southern America. Subsurface imaging could also be achieved in polar permafrost regions. The capability of subsurface imaging is of interest in the exploration of the Martian surface. Many areas on Mars are likely to be covered by dust layers resulting from the large scale dust storms occurring regularly, or by ash resulting from past volcanic activity. Because of the low mean surface temperature, any moisture in the topsoil (if present at all) would be completely frozen for most of the Martian year, thus being of low absorbtivity. The covering layers might hide surface features which could shed more light on the erosional processes previously active. It would also be of interest to image the Martian polar caps and the polar layered deposits associated with the caps.

\section{ACKNOWLEDGMENT}

The authors acknowledge the help of R. Blom and W. Stromberg of JPL, who processed and enhanced the images shown in Fig. 2 and on the cover.

\section{REFERENCES}

[1] R. G. Blom, R. J. Crippen, and C. Elachi, "Detection of subsurface features in Seasat radar images of Means Valley, Mojave Desert California," submitted to Geology, Oct. 1983.

[2] M. Born and E. Wolf, Principles of Optics, 4th ed. London: Pergamon, 1970 , p. 40.

[3] M. J. Campbell and J. Ulrichs, "Electrical properties of rocks and their significance for lunar radar observations," J. Geophys. Res., vol. 74, pp. 5867-5881, 1969.

[4] C. Elachi, W. E. Brown, J. B. Cimino, T. Dixon, D. L. Evans, J. P. Ford, R. S. Saunders, C. Breed, H. Masursky, J. P. McCauley, G. Schaber, L. Dellwig, A. England, H. MacDonald, P. Martin-Kaye, and F. Sabins, "Shuttle imaging radar experiment," Science, vol. 218, pp. 996-1003, 1982.

[5] J. F. McCauley, G. G. Schaber, C. S. Breed, M. J. Grolier, C. V. Haynes, B. Issawi, C. Elachi, and R. Blom, "Subsurface valleys and geoarcheology of eastern Sahara revealed by shuttle radar," Science, vol. 218, pp. 1004-1019, 1982.

[6] G. Olhoeft, USGS Denver, private communication.

[7] G. R. Valenzuela, "Depolarization of EM waves by slightly rough surfaces," IEEE Trans. Antennas Propagat., vol. AP-15, pp. 552$557,1967$.

[8] G. R. Valenzuela, "Scattering of electromagnetic waves from tilted slightly rough surfaces," Radio Sci., vol. 3, pp. 1057-1066, 1968.

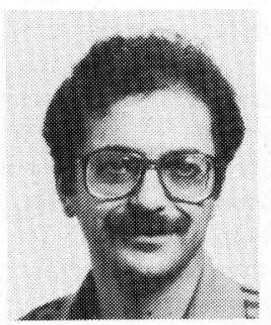

Charles Elachi (M'71-SM'82) was born in Lebanon on April 18, 1947. He received the Ingenieur degree with honors in radioelectricity and the "Prix de la Houille Blanche" from the Polytechnic Institute of Grenoble, Grenoble, France, in 1968 and the B.S. degree in physics from the University of Grenoble in 1968. He received the M.S. and Ph.D. degrees in electrical sciences from the California Institute of Technology, Pasadena, in 1969 and 1971 , respectively.

He has worked at the Physical Spectrometry Laboratory, University of Grenoble, France, on plasma in microwave cavities. He was a Teaching Assistant at the California Institute of Technology in 1969. In 1970, he joined the Space Sciences Division, Jet Propulsion Laboratory, Pasadena, where he is presently a Senior Research Scientist involved in investigating spacecraft-borne scientific experiments for planetary and Earth studies using coherent radar techniques. Since 1980, he has been the Manager for Radar Development, which covers all aspects of the radar remote-sensing program at JPL. He was the Principal Investigator on the Shuttle Imaging Radar (SIR-A) which flew in 1981, and is also the Principal Investigator on the followon SIR-B experiment scheduled for 1984. He has been involved in studying theoretical electromagnetic problems related to scattering from natural terrain, remote sensing, stratified media, space-time periodic media, and DFB lasers. He has 150 papers, patents, reports, and conference presentations in the above fields. He also lectures at the California Institute of Technology on the "Physics of Remote Sensing."

In 1973, Dr. Elachi was the first recipient of the R.W.P. King award. In 1980 , he received the Autometric Award of the American Pho- 
togrammetric Society. He is a member of the AAAS, ADS, AGU, and Sigma Xi.

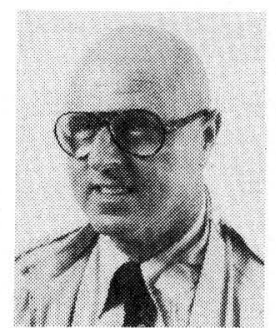

Ladislav E. Roth (M'82) was born in Kosice, Slovakia. He received the Dipl. Ing. degree in electrical engineering from the Czech Institute of Technology, Prague, Czechoslovakia, and the M.Sc. degree in planetary and space physics from the University of California, Los Angeles.

$\mathrm{He}$ is currently a Senior Scientist with the Altimetry and Topography Group of the Jet Propulsion Laboratory, California Institute of Technology, Pasadena, and is a Principal Investigator in the NASA Planetary Geology Program. His research interests include physical properties of surfaces of the terrestrial planets, processes on those surfaces, and interpretation of radar and imaging data.

Mr. Roth is a member of the American Geophysical Union and the Society for Industrial and Applied Mathematics.

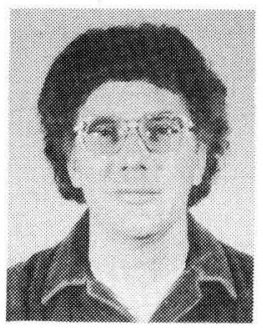

Gerald G. Schaber received the B.S. degree in geology from the University of Kentucky, Lexington, in 1960 and the M.S. and Ph.D. degrees from the University of Cincinnati, Cincinnati, $\mathrm{OH}$, in 1962 and 1965, respectively.

$\mathrm{He}$ is currently a Supervisory Geologist with the U.S. Geological Survey's Branch of Astrogeology, Flagstaff, AZ, where he is currently Chief of that branch. His current research activities include terrestrial and planetary radargeology and planetary geology studies. For the past 15 years, he has been a leader in the development of procedures for the utilization of microrelief terrain roughness statistics in radar backscatter modeling. He is presently playing a major role in assessing the geologic significance of recently demonstrated space Shuttle Imaging Radar (SIR-A) signal penetration through the sands of the Sahara in Egypt and Sudan.

Dr. Schaber was a corecipient of the 1982 Autometrics Award of the American Photogrammetric Society for his work on SIR-A signal penetration mentioned earlier.

\title{
Comparison of Three In Situ Surface Soil Moisture Measurements and Application to $C$-Band Scatterometer Calibration
}

\author{
R. BERNARD, O. TACONET, D. VIDAL-MADJAR, J. L. THONY, M. VAUCLIN, A. CHAPOTON, \\ F. WATTRELOT, AND A. LEBRUN
}

\begin{abstract}
C-band scatterometers can be used to measure the surface soil moisture. This technique does not directly give the water content and a signal calibration is necessary. This is done by comparing the scatterometer signal (expressed as a scattering cross section per unit area) to gravimetric samples. The gravimetric sample calibration takes a lot of time and people, hence it is not adapted to airborne or satellite remote-sensing measurements. In this paper, new automatic equipment based on the measurement of the real part of the complex permittivity of moist soil is presented. The results of a one-month experiment show that this technique is well adapted to the automatic monitoring of soil moisture in general. In particular, it can be used for the calibration of microwave remote-sensing equipment.
\end{abstract}

Manuscript received October 14, 1982; revised December 22, 1983. This work was supported by the French Centre National d'Etudes Spatiales.

R. Bernard, O. Taconet, and D. Vidal-Madjar are with C.R.P.E., 38/40, rue du Général Leclerc, 92131-Issy-les-Moulineaux, France.

J. L. Thony and M. Vauclin are with I.M.G., BP 53 X, 38041 GrenobleCedex, France.

A. Chaponton is with C.H.S., Université des Sciences et des Techniques, 59655-Villeneuve d'Ascq, France.

F. Wattrelot and A. Lebrun are with C.R.E.S.M.A.T., Université des Sciences et des Techniques, 59655 -Villeneuve d'Ascq, France.

\section{INTRODUCTION}

$\mathrm{T}$ HE CAPABILITY of a $C$-band scatterometer to measure the surface soil moisture was first demonstrated by the University of Kansas experiments [1]-[4] and subsequently by several other laboratories using either crane-mounted or airborne radars. In such experiments, the calibration of the scatterometer signal has always been done by using gravimetric sampling of surface soil moisture. Such a technique, which is considered a reference measurement, is incompatible with an air- or satelliteborne mission for soil moisture at the regional scale: it requires too many people and too much time for calibration and it cannot be implemented on more than one or two sites. In the near future, with the development of several airborne systems, the demand for a more practical means of obtaining surface soil moisture measurements will develop. The method must include several conditions; it must:

i) present a good correlation with the gravimetric sampling, ii) be able to account for the spatial variability of the 